TRADITIONAL MEDICINE AND PHARMACOLOGY. ACHIEVEMENTS, INNOVATIONS, AND ALTERNATIVES

\title{
SECTION 4. OVERWEIGHT AND OBESITY THE ROLE OF FOOD BEHAVIOUR AND MENTAL FEATURES OF PERSONALITY
}

\subsection{Overweight and obesity: the role of food behaviour and mental features of personality}

\subsubsection{REVIEW OF LITERATURE}

\subsubsection{Overweight and obesity are a non-infectious modern pandemic}

Obesity is a chronic recurrent disease characterized by excessive accumulation of adipose tissue in the body.

WHO considers obesity to be an epidemic affecting millions of people: according to the 10th International Congress on Obesity (Sydney, September 2019), more than 250 million obese people are registered worldwide. Today, in most Western European countries, obesity (BMI $>30 \mathrm{~kg} / \mathrm{m}^{2}$ ) affects 10 to $25 \%$ of the population, in the United States - 20 to $25 \%$. Overweight (BMI $>25 \mathrm{~kg} / \mathrm{m}^{2}$ ) in industrialized countries, except Japan and China, is about half the population In many countries around the world over the past 10 years, the incidence of obesity has doubled on average. WHO experts estimate that by 2025 the number of obese people in the world will be 300 million. There is an increase in the number of obese children. According to researchers, if obesity grows at the same rate, then by 2230 the entire US population will be overweight. Among the working population of Ukraine, obesity is found in almost $30 \%$ of cases, and every fourth inhabitant is overweight [242].

The importance of obesity is determined by the risk of disability in young patients and the reduction in overall life expectancy due to the development of severe comorbidities. Diseases that accompany obesity include type 2 diabetes, hypertension, dyslipidemia, atherosclerosis and related diseases, sleep apnea, hyperuricemia, gout, reproductive dysfunction, gallstones, osteoarthritis, cancer (in women - cancer of the endometrium, cervix, ovaries, mammary glands, in men - prostate cancer, rectal cancer in both sexes), varicose veins of the lower extremities, hemorrhoids. Concomitant diseases, especially cardiovascular, usually develop in obese patients at a young age. The probability of their development increases with weight gain. 
The risk of concomitant diseases is also determined by the peculiarities of adipose tissue deposition. The most unfavorable for health is the abdominal type of obesity, which is combined with a complex of hormonal and metabolic disorders [243].

\subsubsection{Etiological and pathogenetic structure of obesity}

Obesity is a multifactorial, heterogeneous disease.

Factors that determine the development of obesity include:

- genetic;

- demographic (age, gender, ethnicity);

- socio-economic (education, profession, marital status);

- psychological;

- behavioral (nutrition, physical activity, alcohol, smoking, stress).

Determinants among these factors are overeating, excessive consumption of fatty foods in combination with low physical activity in people with a hereditary predisposition to obesity. Obesity is the result of a long-term violation of the energy balance, when the energy intake in the body exceeds its energy expenditure. An important component of the mechanisms of pathogenesis of obesity is the actual adipose tissue, which has endo-, auto- and paracrine functions.

Substances secreted by adipose tissue have a variety of biological effects and can affect the activity of metabolic processes in tissues and various systems of the body both directly and indirectly through the neuroendocrine system, interacting with pituitary hormones, catecholamines, insulin.

Adipose tissue secretes:

- leptin;

- tumor necrosis factor- $\alpha$ (TNF- $\alpha)$;

- interleukin-6;

- free fatty acids (FFA);

- protein that stimulates acetylation;

- plasminogen activator inhibitor-1 (IAP-1);

- transforming growth factor B;

- angiotensinogen. 
Adipose tissue also contains important regulators of lipoprotein metabolism: lipoprotein and hormone-sensitive lipase; a protein that carries cholesterol esters.

The function of adipose tissue, in turn, is affected by catecholamines, corticosteroids, insulin. Of great importance in the regulation of energy metabolism is the CNS system: the hypothalamus - adipose tissue, the key link of which is leptin. It is believed that the function of leptin is aimed mainly at conserving energy reserves, ie the adequacy of fat accumulation. Leptin is also considered an integrator of neuroendocrine functions.

Obesity is characterized by hyperleptinemia, which is considered to be a consequence of leptin resistance. It is likely that adipose tissue as an endocrine organ performs adipostatic function, and under conditions of long-term positive energy balance and weight gain develops a state of adipose tissue dysfunction, enhances its secretory function, which leads to metabolic disorders accompanying obesity.

\subsubsection{Clinical criteria and classification of overweight and obesity}

Body weight index (BMI) is used to verify obesity, which is calculated as the ratio of body weight $(\mathrm{kg})$ to height $\left(\mathrm{m}^{2}\right)$.

The nature of the distribution of adipose tissue is determined by the ratio of waist circumference/hip circumference (WC/HC).

The value of $\mathrm{WC} / \mathrm{HC}$ for men $>1.0$ and women $>0.85$ indicates the abdominal type of obesity.

An indicator of the clinical risk of developing metabolic complications of obesity is also the size of the waist circumference.

Classifications of obesity

Today use the following classifications of obesity:

1. On the etiological principle:

- alimentary-constitutional;

- hypothalamic;

- endocrine;

- iatrogenic.

2. By type of adipose tissue deposition: 
TRADITIONAL MEDICINE AND PHARMACOLOGY. ACHIEVEMENTS, INNOVATIONS, AND ALTERNATIVES

- abdominal (android, central);

- gynoid (buttock-femoral);

- mixed.

3. According to the body mass index (WHO, 1997)

BMI classification is used to diagnose obesity, determine the risk of comorbidities and tactics of treatment of obese patients [244].

\subsubsection{The role of eating behavior in the formation of overweight and} obesity

Eating disorders are one of the leading factors in weight gain and obesity. Eating behaviour (EB) is a set of eating habits, both in everyday life and in stressful situations, as well as attitudes towards eating. That is, EB includes attitudes, habits and emotions related to food and are individual to each person.

Healthy human EB is characterized by four main parameters

1. Unconditional permission to eat. A person with healthy EB eats what and when he wants, he does not deny himself food when he is hungry. Such behavior does not impose restrictions on any products and is not controlled by a specific time frame.

2. Eating for physical rather than emotional reasons. With healthy $\mathrm{EB}$, food does not play the role of a regulator of emotional experiences. Its only function is to meet the physiological needs for energy and nutrients. And to establish emotional comfort, the skills of emotional regulation are used.

3. Trust the body's internal signals. At disorders of EB contact with internal signals of an organism, including with those regulating food process is almost always broken. The signals of hunger a person can ignore, and catches them only when he growls loudly in the stomach. The feeling of satiety is also not caught - a person regulates the amount eaten, guided only by external rules, not the needs of the body and feelings in it.

4. Choosing food according to the needs of the body. Attentiveness to one's own dietary desires is part of a healthy EB. It manifests itself in attempts to understand before eating what you want most now and include it in your diet. Understanding what 
TRADITIONAL MEDICINE AND PHARMACOLOGY. ACHIEVEMENTS, INNOVATIONS, AND ALTERNATIVES

you want, again, should be based on the sensations in the body, not on considerations of what and when to "eat" right.

There is no generally accepted classification of EB violations today. Some researchers suggest identifying three conditional types of EB disorder: restrictive, emotional, and external [245].

Restrictive type of EB is excessive food self-restraint and unsystematic diets. Periods of restrictive type of EB are replaced by periods of overeating with a new intensive weight gain. These periods lead to emotional instability - dietary depression [246-247].

Emotional type of EB - hyperphagic reaction to stress, emotional overeating. With this behavior, the stimulus for food intake is not hunger, but emotional discomfort; food in response to stress, depression; night eating syndrome; morning anorexia; evening and night meals; insomnia; compulsive type of EB; recurrent episodes of overeating; a clear state of distress due to the presence of such episodes [247].

External type of EB is manifested by an increased human response not to internal, homeostatic stimuli to eating, but to external. In this type of EB, the availability of products is of crucial importance; hyperactivity to food stimuli: appearance of food, smell, taste; food for the company; frequent snacks. Unadjusted strict diet leads to dietary depression, exacerbation of emotional instability, self-doubt, refusal to continue to follow a rational diet, loss of cell mass instead of fat, decreased basal metabolism and subsequent weight gain [247].

In addition to exogenous factors, gender and age have a huge influence on the type of EB in overweight and obese people. The difference in the intensity of metabolism, endocrine and neuropsychological backgrounds, the peculiarities of the constitution, among obese people of different ages and genders, necessitates the need to take into account the above factors at the stage of corrective therapy to obtain lasting positive results in a shorter period of treatment. Of all the questionnaires on the 
TRADITIONAL MEDICINE AND PHARMACOLOGY. ACHIEVEMENTS, INNOVATIONS, AND ALTERNATIVES

detection of EB disorders, the simplest, most convenient and fastest to use is the DEBQ questionnaire.

Thus, EB disorders can be considered as a leading factor in the development of overweight and obesity, and corrective therapy must take into account the gender and age characteristics of patients.

\subsubsection{The relationship between mental characteristics and the} development of obesity

Clinical studies have found that overweight and obese patients are more likely to develop the following mental disorders, which are considered highly specific symptoms for such conditions. First of all, it does not explain that there are periodic outbreaks of nakedness and the desire to eat something sweet. The second is a constant feeling of fatigue and exhaustion. The third is irritability, fits of anger, panic fear, and a state of tearfulness. Obese patients often show distrust of others and the motives of their actions, even if they are altruistic [248-249]. Studies of the psychological characteristics of obese patients have revealed a frequent occurrence of such cognitive problems as hypomnesia, decreased attention. Independent and very important place among the recorded disorders in patients of this category is occupied by disorders of sexual behavior, including decreased libido, erectile dysfunction.

The following are options for mental disorders that occur in obesity and described in the works of various authors:

- asthenic disorders [254];

- endocrine psychosyndrome [248];

- anxiety disorders [242-245, 258];

- affective disorders (often depressive) [242-244, 254-256];

- behavioral disorders [242, 243, 247, 250];

- cognitive disorders [252];

- sleep disorders not caused by depression [249];

Endocrine psychosyndrome in obesity has been described as an independent concept [249]. Its clinical characteristics, first of all, include personality changes: 
TRADITIONAL MEDICINE AND PHARMACOLOGY. ACHIEVEMENTS, INNOVATIONS, AND ALTERNATIVES

affective personality changes, namely - a violation of the sphere of instincts, urges, moods.

The second feature of such disorders is that personality changes are not gross. In most patients, this psychosyndrome is characterized by variability and polymorphism. However, there is a clear movement from pronounced personality changes to psychoorganic syndrome with a predominance of mnestic disorders [250-254]. Decreased mental activity also has a negative trend. An obese patient is often diagnosed with increased exhaustion and passivity in asthenic conditions. But as the duration of obesity increases, asthenia develops into complete spontaneity with a significant reduction in interest and autism. The sphere of urges and instincts suffers greatly in such patients. Such patients are characterized by a decrease or absence of sexual desire, appetite, thirst. Wandering, changing sleep needs, warm and other psychophysical phenomena are often registered, which indicate gross violations in the field of vital feelings and urges [255-258].

It is important to note that mood disorders in obese patients are differently figurative and have different severity. Mixed states, such as depression with dysphoria, anxiety, manic and depressive states with malice and hatred, depressed apathy, asthenia, depression predominate. According to the world literature, the high written weight of depressive disorders in obese patients is growing [259].

Especially often weight gain occurs against the background of anxiety depression, when the urge to eat is activated, there is a feeling of insatiable hunger, craving for food rich in carbohydrates. As a result, the metabolic syndrome develops or its clinic amplifies and complications are formed.

\subsubsection{MATERIALS AND METHODS OF OWN RESEARCH}

\subsubsection{Characteristics of patient groups}

Determination of the types of EB in overweight and obesity, depending on gender and age factors was conducted on the basis of the University Clinic of the Black Sea National University named after Petro Mohyla and the clinic of the State Institution "Territorial Medical Association of the Ministry of Internal Affairs of Ukraine in Mykolaiv region" 210 people (105 women and 105 men). The age of women ranged 
from 19 to 60 years (mean age was $41.5 \pm 11.2$ years), the age of men - from 22 to 60 years (mean age $-42.3 \pm 12.3$ years).

All patients were divided into two clinical groups: 1st group - 70 people (35 women and 35 men) with excess weight (body mass index (BMI) from 25.8 to 29.3 $\mathrm{kg} / \mathrm{m}^{2}$, average $27.5 \pm 1.31 \mathrm{~kg} / \mathrm{m}^{2}$ ); 2nd group - 72 people (36 women and $36 \mathrm{men}$ ) with 1st degree obesity (BMI from 30.0 to $33.9 \mathrm{~kg} / \mathrm{m}^{2}$; average $31.74 \pm 1.03 \mathrm{~kg} / \mathrm{m}^{2}$ ). The control group consisted of 70 people ( 35 women and 35 men) with normal weight (BMI from $19.5 \mathrm{~kg} / \mathrm{m}^{2}$ to $23.9 \mathrm{~kg} / \mathrm{m}^{2}$; average $22.41 \pm 1.43 \mathrm{~kg} / \mathrm{m}^{2}$ ). In each of the groups studied the features of EB separately in women and men under 45 years and after 45 years.

All patients had anthropometric (height, weight, abdominal circumference, thigh circumference), and physiological (blood pressure, heart rate and respiratory rate) parameters calculated by BMI and waist/thigh index.

\subsubsection{Anthropometric and physiological indicators of different clinical} groups

Anthropometric and physiological parameters for each of the groups of patients depending on gender are given in table $\mathbf{1}$. 
TRADITIONAL MEDICINE AND PHARMACOLOGY. ACHIEVEMENTS, INNOVATIONS, AND ALTERNATIVES

Table 1. Anthropometric and physiological parameters of patients of different clinical groups

\begin{tabular}{|c|c|c|c|c|c|c|}
\hline \multicolumn{7}{|l|}{ Indexes } \\
\hline & \multicolumn{2}{|l|}{ Control group } & \multicolumn{2}{|l|}{ 1st group } & \multicolumn{2}{|l|}{ 2nd group } \\
\hline & women & men & women & men & women & men \\
\hline \multicolumn{7}{|l|}{ Anthropometric: } \\
\hline \multirow{3}{*}{ height, $\mathrm{cm}$} & $155-170$ & $168-180$ & $157-171$ & $167-179$ & $155-172$ & $168-180$ \\
\hline & $(162,51 \pm 3,03)$ & $(174,01 \pm 6,03)$ & $(163,51 \pm 2,03)$ & $(173,01 \pm 5,03)$ & $(164,51 \pm 3,03)$ & $(174,51 \pm 6,03)$ \\
\hline & $55-70$ & $65-80$ & $70-83$ & $75-89$ & $80-93$ & $80-110$ \\
\hline \multirow[t]{2}{*}{ weight, $\mathrm{kg}$} & $(67,52 \pm 5,21)$ & $(72,51 \pm 4,21)$ & $(76,52 \pm 5,21)$ & $(82,50 \pm 4,21)$ & $(86,50 \pm 6,21)$ & $(95,31 \pm 5,21)$ \\
\hline & $60-75$ & $76-88$ & $70-85$ & $80-88$ & $84-92$ & $80-88$ \\
\hline \multirow[t]{2}{*}{ waist circumference, $\mathrm{cm}$} & $(67,5 \pm 2,2)$ & $(82,2 \pm 3,2)$ & $(77,5 \pm 2,3)$ & $(84,01 \pm 4,01)$ & $(88,5 \pm 2,1)$ & $(89,5 \pm 1,1)$ \\
\hline & $86-90$ & $94-96$ & $90-96$ & $98-101$ & $94-100$ & $99-105$ \\
\hline \multirow{2}{*}{ thigh circumference, $\mathrm{cm}$} & $(88,0 \pm 2,2)$ & $(95 \pm 1)$ & $(93,0 \pm 2,2)$ & $(99,5 \pm 1,0)$ & $(97,0 \pm 2,2)$ & $(100,5 \pm 1,1)$ \\
\hline & $0,75-0,80$ & $0,82-0,84$ & $0,85-0,90$ & $0.90-0,95$ & $0,89-0,95$ & $0,99-1,02$ \\
\hline $\begin{array}{l}\text { index, } \\
\text { waist/hips }\end{array}$ & $(0,76 \pm 0,04)$ & $(0,83 \pm 0,01)$ & $(0,87 \pm 0,04)$ & $(0,92 \pm 0,01)$ & $(0,92 \pm 0,03)$ & $(1,01 \pm 0,01)$ \\
\hline
\end{tabular}

Physiological:

\begin{tabular}{|c|c|c|c|c|c|c|}
\hline & $110 / 65-130 / 75$ & $120 / 65-130 / 75$ & $120 / 75-140 / 90$ & $135 / 75-140 / 80$ & $135 / 75-170 / 90$ & $135 / 75-160 / 90$ \\
\hline blood pressure, $\mathrm{mm}$ hg & $(120 / 70 \pm 10 / 10)$ & $(125 / 75 \pm 10 / 10)$ & $(130 / 82 \pm 10 / 10)$ & $(135 / 82 \pm 10 / 10)$ & $(155 / 92 \pm 15 / 15)$ & $148 / 85 \pm 13 / 12)$ \\
\hline
\end{tabular}


TRADITIONAL MEDICINE AND PHARMACOLOGY. ACHIEVEMENTS, INNOVATIONS, AND ALTERNATIVES

\begin{tabular}{|c|c|c|c|c|c|c|}
\hline & $64-74$ & $65-75$ & $70-79$ & $69-82$ & $72-79$ & $70-82$ \\
\hline heart rate, number of & $(69 \pm 4)$ & $(70 \pm 2)$ & $(74,5 \pm 5,1)$ & $(75,0 \pm 5,2)$ & $(75,5 \pm 5,2)$ & $76,3 \pm 6,2)$ \\
\hline \multicolumn{7}{|l|}{ beats per minute } \\
\hline & $16-18$ & $16-18$ & $18-20$ & $17-19$ & $18-20$ & $17-19$ \\
\hline respiratory rate, number & $(17 \pm 1)$ & $(17 \pm 1)$ & $(19 \pm 1)$ & $(18,0 \pm 1,2)$ & $(19 \pm 1)$ & $(18,01 \pm 1,02)$ \\
\hline \multicolumn{7}{|l|}{ of respiratory } \\
\hline movements per minute & & & & & & \\
\hline
\end{tabular}

Note: the minimum and maximum values (average value and standard error of the average) of the corresponding indicators are presented 
TRADITIONAL MEDICINE AND PHARMACOLOGY. ACHIEVEMENTS, INNOVATIONS, AND ALTERNATIVES

\subsubsection{DEBQ (Dutch Eating Behavior Questionnaire) Patient Survey}

\section{Methodology}

EB disorders were assessed using a DEBQ questionnaire adapted to the purpose of the study, which contained 33 questions. Each answer was evaluated with 5 points: never - 1 point, rarely - 2 points, sometimes - 3 points, often -4 points and very often - 5 points. The only exception was question number 31 , where the points were distributed in reverse order: never - 5 points, rarely - 4 points, sometimes - 3 points, often - 2 points and very often - 1 point. The questionnaire was supplemented with questions about the presence of heredity in the families of the respondents, the frequency of meals and the use of hormonal drugs. The first block of the questionnaire focused on the patient's gender, age, professional activity and ethnicity.

The results of the answers to the first 10 questions of the questionnaire corresponding to the restrictive type of EB were added and divided by 10, and the obtained result was compared with the normative indicator for the restrictive type of EB $(2,4)$. The results of the answers to questions 11 to 23 of the questionnaires corresponding to the emotional type of EB were added and divided by 13, and the obtained result was compared with the normative indicator for the emotional type of EB $(1,8)$. The results of answers to questions 24 to 33 of the questionnaire, corresponding to the external type of EB, were added and divided by 10 , and the result was compared with the norm for the external type of EB (2.7).

Statistical processing of research results was carried out by methods of variation statistics using a standard application package SPSS 13.0 for MS Windows. Descriptive statistics were used for statistical analysis of data; comparison of the average values of the variables was carried out using parametric methods (Student's ttest) with a normal distribution of these features, expressed in the interval scale. Fisher's exact test was used to compare the particle distribution of two or more variables. The difference was considered significant if the achieved significance level (p-value) was lower than 0.05 . 
TRADITIONAL MEDICINE AND PHARMACOLOGY. ACHIEVEMENTS, INNOVATIONS, AND ALTERNATIVES

The study was conducted in accordance with the basic bioethical norms of the Helsinki Declaration of the World Medical Association "Ethical principles of medical research with human participation as an object of study" (1964), as amended, the Universal Declaration on Bioethics and Human Rights of the United Nations (2005), the Council of Europe Convention on Human Rights and Biomedicine (1997). All participants were informed about the goals, organization, research methods and signed an informed consent to participate in it. All measures were also taken to ensure the anonymity of patients.

\subsubsection{RESULTS AND DISCUSSION OF RESEARCH RESULTS}

\subsubsection{The structure of types of eating behavior in overweight and obese} patients

The study found that the types of EB patients had a certain dependence on BMI. In all clinical groups, the leading disorder was EB by restrictive type.

The distribution of EB types among patients in the control group with an average BMI of $22.41 \pm 1.43 \mathrm{~kg} / \mathrm{m}^{2}(\mathrm{n}=70)$ was as follows: healthy type of EB - in 43 people (61.4\%), restrictive type of EB - in 9 people 12.8\%), emotional type of EB - in 5 people (7.1\%) and exogenous type of EB - in 13 people (18.7\%), (table 2).

The corresponding indicator among patients of the 1st group with an average BMI of $27.51 \pm 1.31 \mathrm{~kg} / \mathrm{m}^{2}(\mathrm{n}=70)$ was: healthy type of EB - in 8 people $(11.4 \%)$, restrictive type of EB - in 31 people $44.3 \%$ ), emotional type of EB - in 4 people (5.7\%) and exogenous type of EB - in 27 people (38.6\%), (table 2).

The distribution of EB types in patients of the 2nd group with an average BMI of $31.74 \pm 1.03 \mathrm{~kg} / \mathrm{m}^{2}(\mathrm{n}=92)$ was: healthy type - in 4 people $(5.5 \%)$, restrictive type of EB - in 34 people (48.5\%), emotional type of EB - in 5 people (7.1\%) and exogenous type of EB - in 29 people (38.9\%), (table 2).

In all clinical groups, the disorder was the leading type of restrictive EB. Compared with the control group among patients of the 1st group, the disorder of the restrictive type of EB was recorded 3.44 times more often $(D=0.161, p=0.046<0.05)$, the disorder of the external type of EB - 7 times more often $(\mathrm{D}=0.310, \mathrm{p}=0.001$ 
TRADITIONAL MEDICINE AND PHARMACOLOGY. ACHIEVEMENTS, INNOVATIONS, AND ALTERNATIVES

$<0.05)$, and a healthy type of EB - 5.38 times less often $(\mathrm{D}=13.561, \mathrm{p}=0.002<0.05)$

(Table 2). Thus, a comparison of EB disorders in overweight and normal weight patients showed that with increasing patient weight, the percentage of EB disorders increases, mainly due to the dominance of the restrictive type of EB.

Among patients of the 2nd group the restrictive type of EB was also leading and in comparison with the control group was recorded 3.78 times more often $(D=0.153$, $\mathrm{p}=0.061<0.05)$, the disorder of the exogenous type of EB - in 2.23 times more often $(\mathrm{D}=0.281, \mathrm{p}=0.001<0.05)$, and a healthy type of $\mathrm{EB}-10.75$ times less often ( $\mathrm{D}=$ $21.043, \mathrm{p}=0.022<0.05$ ), (table 2). That is, patients with overweight and obesity maintain a similar trend: with increasing BMI, the percentage of eating disorders increases, especially due to the restrictive type. 
TRADITIONAL MEDICINE AND PHARMACOLOGY. ACHIEVEMENTS, INNOVATIONS, AND ALTERNATIVES

Table 2. Types of eating behaviour (EB) among patients of different clinical groups

\begin{tabular}{|c|c|c|c|c|c|c|c|c|c|c|c|c|}
\hline \multirow[t]{2}{*}{ Types of EB } & \multicolumn{2}{|c|}{$\begin{array}{l}\text { Control group } \\
(n=70)\end{array}$} & \multicolumn{2}{|c|}{$\begin{array}{l}\text { 1st group } \\
(n=70)\end{array}$} & \multicolumn{2}{|c|}{$\begin{array}{l}\text { 2nd group } \\
(n=72)\end{array}$} & \multicolumn{2}{|c|}{$\begin{array}{l}\text { The difference } \\
\text { between the } \\
\text { control and 1st } \\
\text { groups }\end{array}$} & \multicolumn{2}{|c|}{$\begin{array}{l}\text { The difference } \\
\text { between the } \\
\text { control and } 2 \text { nd } \\
\text { groups }\end{array}$} & \multicolumn{2}{|c|}{$\begin{array}{l}\text { The difference } \\
\text { between } \\
\text { 1st and 2nd } \\
\text { groups }\end{array}$} \\
\hline & $\mathbf{n}$ & $\%$ & $\mathbf{n}$ & $\%$ & $\mathbf{n}$ & $\%$ & n & $\%$ & $\mathbf{n}$ & $\%$ & n & $\%$ \\
\hline Healthy & 43 & 61,4 & 8 & 11,4 & 4 & 5,5 & 13,567 & 0,002 & 21,043 & 0,022 & 0,501 & 0,037 \\
\hline Restrictive & 9 & 12,8 & 31 & 44,3 & 34 & 48,5 & 0,161 & 0,046 & 0,153 & 0,061 & 0,902 & 0,051 \\
\hline Emotional & 5 & 7,1 & 4 & 5,7 & 5 & 7,1 & 0,532 & 0,400 & 0,480 & 0,280 & 1,910 & 1,000 \\
\hline External & 13 & 18,7 & 27 & 38,6 & 29 & 38,9 & 0,310 & 0,001 & 0,281 & 0,001 & 0,942 & 0,041 \\
\hline
\end{tabular}


The relationship between BMI and type of EB was found among control patients $\left(x^{2}=15.592, p=0.001<0.05\right), 1$ st $\left(x^{2}=\right.$ $41.179, \mathrm{p}=0.001<0.05)$ and $2 \mathrm{nd}\left(\mathrm{x}^{2}=11.005, \mathrm{p}=0.011<0.05\right)$ groups, (table 3$)$.

Table 3. Relationship between the type of EB and the sex of patients in different clinical groups

\begin{tabular}{|c|c|c|c|c|c|c|c|c|c|c|c|c|}
\hline \multirow[t]{2}{*}{ Types of EB } & \multicolumn{4}{|c|}{$\begin{array}{l}\text { Control group } \\
(n=70)\end{array}$} & \multicolumn{4}{|c|}{$\begin{array}{l}\text { 1st group } \\
(n=70)\end{array}$} & \multicolumn{4}{|c|}{$\begin{array}{l}\text { 2nd group } \\
(n=72)\end{array}$} \\
\hline & n & $\%$ & $\chi^{2}$ & p-value & n & $\%$ & $\chi^{2}$ & p-value & n & $\%$ & $\chi^{2}$ & p-value \\
\hline Healthy & 43 & 61,4 & 15,592 & 0,001 & 8 & 11,5 & 41,179 & 0,001 & 4 & 5,5 & 11,005 & 0,011 \\
\hline Restrictive & 9 & 12,8 & & & 31 & 44,2 & & & 34 & 48,5 & & \\
\hline Emotional & 5 & 7,1 & & & 4 & 5,8 & & & 5 & 7,1 & & \\
\hline External & 13 & 18,7 & & & 27 & 38,5 & & & 29 & 38,9 & & \\
\hline
\end{tabular}


TRADITIONAL MEDICINE AND PHARMACOLOGY. ACHIEVEMENTS, INNOVATIONS, AND ALTERNATIVES

\subsubsection{Features of eating behavior in obese patients, depending on gender} and age factors

Gender analysis of EB disorders in overweight and obese people revealed a relationship between the type of EB disorder and the sex of patients.

In group 1, the restrictive type of EB was observed among women with a mean age of $42.5 \pm 12.2$ years 1.7 times more often than among men with a mean age of 43.3 \pm 12.1 years $(\mathrm{D}=0.852, \mathrm{p}=0.001)$, (table 4$)$. The emotional type of EB in women and men was the same $(D=1,261, p=1,003)$. External type of EB was observed among men 1.3 times more often than in women $(\mathrm{D}=0.731, \mathrm{p}=0.005)$. The healthy type of EB in overweight people was the same among both women and men $(\mathrm{D}=10,421, \mathrm{p}=$ 1,003). Thus, among overweight men, the predominance of EB disorders by external type of EB was recorded, and in women - by restrictive type of EB. 
TRADITIONAL MEDICINE AND PHARMACOLOGY. ACHIEVEMENTS, INNOVATIONS, AND ALTERNATIVES

Table 4. Gender characteristics of EB in overweight people

Types of EB

1st group

2nd group

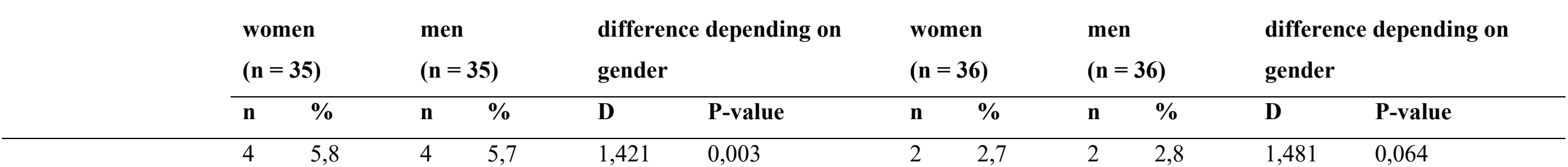

Healthy

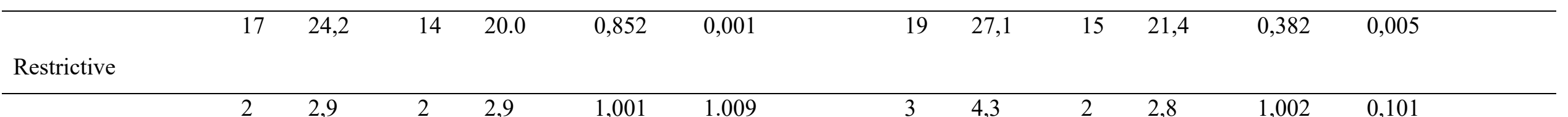

Emotional

$\begin{array}{llllllllllll}12 & 17,1 & 15 & 21,4 & 0,731 & 0,005 & 12 & 16,7 & 17 & 22,2 & 0,861 & 0,008\end{array}$

External 
TRADITIONAL MEDICINE AND PHARMACOLOGY. ACHIEVEMENTS, INNOVATIONS, AND ALTERNATIVES

In group 2, restrictive type of EB was observed among women with a mean age of $41.5 \pm 12.2$ years 1.3 times more often than men with a mean age of $43.0 \pm 12.4$ years $(\mathrm{D}=1,382, \mathrm{p}=0.005)$. Gender differences in the frequency of detection of the emotional type of EB were not detected $(\mathrm{D}=1,001, \mathrm{p}=0,001)$. External type of EB among men was 1.13 times more common than in women $(\mathrm{D}=0.861, \mathrm{p}=0.008)$. Gender differences in the healthy type of EB were not detected $(\mathrm{D}=10,481, \mathrm{p}=0,064)$ (Table 4). Among overweight and obese patients, there was an excess of exogenous EB disorders in men and a predominance of restrictive EB in women.

In the analysis of age-specific features of EB disorders, it was found that the restrictive type of EB was predominant in young people, and the external type was leading among patients after 45 years (table 5). 
TRADITIONAL MEDICINE AND PHARMACOLOGY. ACHIEVEMENTS, INNOVATIONS, AND ALTERNATIVES

Table 5. Age characteristics of EB in overweight people

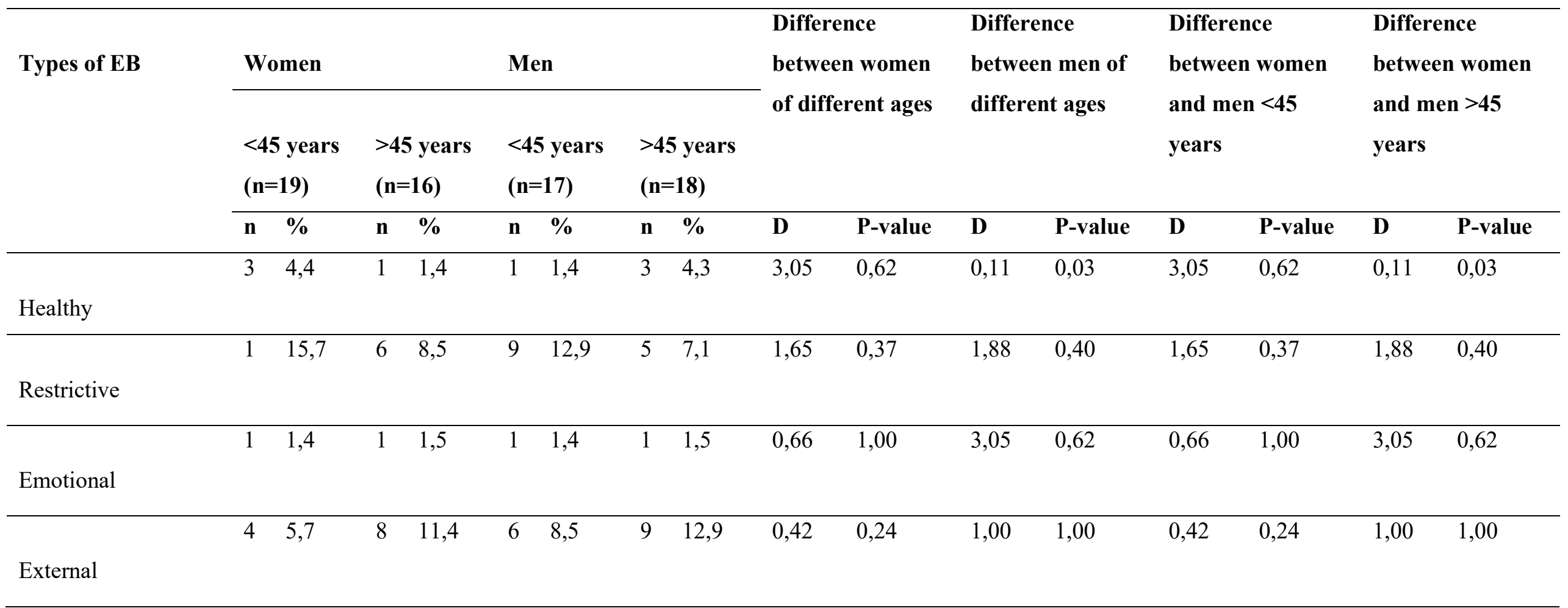


In men of the 1st group after 45 years, a healthy type of EB occurred 8.09 times more often than in men under 45 years of age $(D=0.11, p=0.03<0.05)$, (table 5). This feature suggests that with age men are more demanding when choosing food and more labile to modify their EB and lifestyle.

In women of the 1st group, a healthy type of EB was observed 8.09 times less often than in men of the same age category $(\mathrm{D}=0.11, \mathrm{p}=0.03<0.05)$ (table 5). This fact is probably due to the psychological characteristics of women, namely: a greater tendency to strict diets, a higher percentage of dissatisfaction with their own forms, even with normal BMI, which leads to longer self-limitation in food, and as a consequence of stress, breaking from diets and gaining even more weight than before dieting.

No other probable differences were found in women and men of groups I and II, depending on age (all $p>0.05$ ) (table 5).

СМ ОРИГИНАЛ data show the great interest of scientists around the world to the problem of growth and correction of overweight among obese people [250, 253]. At the same time, the vast majority of authors focus primarily on the modification of EB as a key factor in the development of overweight and obesity [251]. Of course, the refusal of refined food, snacks for the company and night consumption significantly improves the work of the gastrointestinal tract, cardiovascular system of obese and overweight people [246]. At the same time, in our opinion and in the opinion of some researchers, in order to obtain positive results for a shorter course of treatment and achieve a longer rehabilitation period, correction of eating disorders in obese people should be based on gender and age of patients [242, 249 ].

\section{CONCLUSIONS}

1. Eating disorders are one of the leading factors in the development of overweight and obesity: in overweight patients a healthy type of EB was recorded 5.38 times less often than in normal weight $(\mathrm{D}=13,561, \mathrm{p}=0,002<0,05)$, and in obese patients -10.45 times less often than in normal weight individuals $(\mathrm{D}=21.043$, $\mathrm{p}=0.022<0.05)$. 
2. Overweight and obesity are most often associated with a restrictive type of EB. In overweight patients the restrictive type of EB was recorded 3.4 times more often than in people with normal weight $(\mathrm{D}=0.161, \mathrm{p}=0.046<0.05)$, and in obese patients the restrictive type of $\mathrm{CP}$ was recorded 3.78 times more often than in the control group $(\mathrm{D}=0.153, \mathrm{p}=0.061<0.05)$.

3. In all groups, the type of EB is influenced by BMI, sex and age of patients. Thus, in overweight men after the age of 45 a healthy type of EB was observed 8.09 times more often than in men under the age of $45(\mathrm{D}=0.11, \mathrm{p}=0.03<0.05)$ and in women with overweight overweight $(\mathrm{D}=0.11, \mathrm{p}=0.03<0.05)$.

4. In all groups, a correlation was found between the type of EB and the gender and age characteristics of patients.

5. With increasing weight of patients, the number of non-psychotic mental disorders increases, especially due to an increase in asenovegetative, somatoform, anxiety and depressive disorders.

\section{PRACTICAL SIGNIFICANCE AND PROSPECTS OF FURTHER} RESEARCH

Correction of eating disorders in obese people should be carried out taking into account the gender and age of the patient, which will provide positive results with a shorter course of treatment. Medical advice for women and young people, given the prevalence of restrictive disorders of EB, should be aimed at combating strict diets and periods of prolonged starvation, and for men and people over 45 - to follow a balanced diet. The duration of corrective treatment in obese women should be increased with psychotherapy. Taking into account the gender and age characteristics of the patient, individual development of diaries of nutrition and physical activity is the main goal of further research.

The view that obesity and mental disorders develop independently and can be combined at random remains more theoretical, as in practice, even if there are no common biological or genetic mechanisms, psychosocial mechanisms and secondary trauma inevitably occur. Consequently, there is a relationship between these states 
and their interaction. A multispecialized approach in the management of overweight and obese patients, with the involvement of a family doctor, endocrinologist and psychologist - the key to sustainable and positive treatment results.

\section{ABBREVIATION}

Blood pressure - blood pressure

BMI - body mass index

DEBQ - Netherland Eating Behaviour Questionnaire

EB - eating behaviour

FFA - free fatty acids

IAP-1 is an inhibitor of plasminogen-1 activator

SPSS 13.0 for MS Windows - is a computer program for statistical processing of social science data

TC -circumference of the thighs

TNF- $\alpha$ is a tumor necrosis factor- $\alpha$

WC - waist circumference

WC / HC ratio - waist / hip circumference ratio

WHO - World Health Organization 